CLINICAL STUDY

\title{
Comparison of the cortisol responses to testing with two doses of ACTH in patients with suspected adrenal insufficiency
}

\author{
O M Dekkers ${ }^{1,2, *}$, J M Timmermans ${ }^{1, *}$, J W A Smit ${ }^{1}$, J A Romijn ${ }^{1}$ and A M Pereira ${ }^{1}$ \\ Departments of ${ }^{1}$ Endocrinology and Metabolic Diseases and ${ }^{2}$ Clinical Epidemiology, C7-R, Leiden University Medical Center, PO Box 9600, \\ 2300 RC Leiden, The Netherlands \\ (Correspondence should be addressed to O M Dekkers at Department of Clinical Epidemiology, C7-R, Leiden University Medical Center; \\ Email: o.m.dekkers@lumc.nl)
}

*(O M Dekkers and J M Timmermans contributed equally to this work)

\begin{abstract}
Objectives: To compare the cortisol response of the $1 \mu \mathrm{g}$ and the $250 \mu \mathrm{g}$ ACTH test in a large study of patients with suspected adrenal insufficiency.

Design: Retrospective cohort study.

Methods: Single center study assessing patients tested for primary or secondary adrenal insufficiency between January 2004 and December 2007, who had both ACTH tests ( $1 \mu \mathrm{g}$ and $250 \mu \mathrm{g} ; n=207$ ) within a time interval of 6 weeks. Test results were compared with a Bland-Altman plot and McNemar's test.

Results: The mean difference between the cortisol responses in the two ACTH tests was $26 \mathrm{nmol} / \mathrm{l}$ (95\% confidence interval (CI) 13, 40), showing a marginally higher response for the $250 \mu \mathrm{g}$ test. The diagnostic performances of the two tests were similar $(P=0.49)$ using a cut-off value for cortisol of $550 \mathrm{nmol} / \mathrm{l}$. A normal cortisol response to the $1 \mu \mathrm{g}$ ACTH test could be accompanied by an abnormal response to the $250 \mu \mathrm{g} \mathrm{ACTH}$ test, and vice versa.

Conclusion: This study shows that the $1 \mu \mathrm{g}$ and the $250 \mu \mathrm{g}$ ACTH tests have comparable cortisol responses in patients with suspected adrenal insufficiency. However, in individual patients, the difference in cortisol response to the two tests can be substantial, and the response in the $250 \mu \mathrm{g}$ test is not invariably higher than the response in a $1 \mu \mathrm{g}$ test.
\end{abstract}

European Journal of Endocrinology 164 83-87

\section{Introduction}

Adrenal insufficiency is a potentially life-threatening condition characterized by decreased endogenous cortisol production. Adrenal insufficiency is associated with adrenal diseases (primary adrenal insufficiency) such as autoimmune adrenalitis, and with diseases interfering with ACTH production by the pituitary such as pituitary tumors (secondary adrenal insufficiency) (1-3). In addition, adrenal insufficiency can be caused by suppression of the hypothalamic-pituitary-adrenal (HPA) axis by prolonged use of exogenous corticosteroids.

Several tests are available for the assessment of adrenal secretory reserve and for assessment of the complete HPA axis (4). The ACTH test directly assesses cortisol reserve after administration of an i.v. bolus of exogenous ACTH. The cortisol response to ACTH can also be decreased in patients with severe secondary adrenal insufficiency (5). Currently, two doses of ACTH are used for diagnostic purposes in patients with suspected adrenal insufficiency: $1 \mu \mathrm{g}$ and $250 \mu \mathrm{g}$
ACTH $(3,4,6,7)$. The $1 \mu \mathrm{g}$ test is known to be the lowest dose to cause maximal cortisol response (7). There is, however, an ongoing debate about which dose should be used for the initial assessment of adrenal function. For instance, it is suggested that a dose of $250 \mu \mathrm{g} \mathrm{ACTH}$ is a supraphysiological stimulus, not sensitive enough to detect mild secondary adrenal insufficiency $(8-10)$.

The main aim of the present study was to compare the cortisol responses of two ACTH tests $(1 \mu \mathrm{g}$ and $250 \mu \mathrm{g})$ in a large cohort of patients suspected of primary or secondary adrenal insufficiency.

\section{Methods}

\section{Patient selection}

This retrospective diagnostic study was performed at the outpatient clinic of the Endocrinology Department at the Leiden University Medical Center (LUMC). All consecutive patients suspected for primary or secondary 
adrenal insufficiency who underwent both ACTH tests $(1 \mu \mathrm{g}$ and $250 \mu \mathrm{g})$ between January 2004 and December 2007 were eligible for the present analysis. For inclusion, the two ACTH tests should have been performed within a time interval of 6 weeks. We excluded patients using exogenous glucocorticoids for non-endocrine diseases $(n=5)$, and females using oral contraceptives at the time of testing $(n=2)$. A total of 207 patients were included in this study. The ACTH tests were part of the standard diagnostic procedures in our center for patients with suspected adrenal insufficiency. At the time the analysis was performed, no formal approval from the Ethics Committee of the LUMC was needed for retrospective data analysis. All patients were completely informed and gave oral informed consent for the diagnostic performances according to the Dutch law regarding patient care.

\section{Test protocol of the $1 \mu \mathrm{g}$ and the $250 \mu \mathrm{g}$ ACTH test}

Patients arrived at the hospital at $0800 \mathrm{~h}$ in a fasting state. An i.v. catheter was inserted for blood sampling. In all patients, endogenous ACTH and cortisol levels were measured twice with a time interval of $10 \mathrm{~min}$ before the administration of ACTH. For the $1 \mu \mathrm{g} \mathrm{ACTH}$ test, from 1 ampul tetracosactide (Synacthen $0.25 \mathrm{mg} / \mathrm{ml}$, Novartis), a dose of $1 \mu \mathrm{g}$ was administered as a bolus i.v. One microgram of ACTH was prepared as follows: $0.4 \mathrm{ml}$ was extracted from a $1 \mathrm{ml}$ ampul of tetracosactide containing $250 \mu \mathrm{g}$ (Synacthen $0.25 \mathrm{mg} / \mathrm{ml}$ ), and added to $100 \mathrm{cc} \mathrm{NaCl} 0.9 \%$, resulting in an ACTH concentration of $100 \mu \mathrm{g} / 100 \mathrm{ml}$. Subsequently, $1 \mathrm{cc}(=1 \mu \mathrm{g})$ of this solution was extracted for injection.

For the $250 \mu \mathrm{g}$ test, from 1 ampul tetracosactide (Synacthen $0.25 \mathrm{mg} / \mathrm{ml}$ ), a dose of $250 \mu \mathrm{g}$ was administered i.v. Thirty minutes after administration, a blood sample was drawn to measure cortisol concentrations. Monitoring of side effects was routinely performed by the nursing staff for all dynamic tests. According to test protocols in the LUMC, ACTH tests are not performed within 3 months of pituitary surgery.

\section{Cortisol assay}

Cortisol was measured by fluorescence immunoassay on a TDx (Abbott Laboratories). The interassay variation coefficient was $5-6 \%$ above $500 \mathrm{nmol} / \mathrm{l}$ and amounts to $12 \%$ under $200 \mathrm{nmol} / \mathrm{l}$. The detection limit was $20 \mathrm{nmol} / \mathrm{l}$. Cortisol concentrations of $\geq 550 \mathrm{nmol} / \mathrm{l}$ after ACTH stimulation were considered normal cortisol responses (11).

\section{Statistical methods}

For paired binary data, the McNemar test was used. To assess the association between the values of the two ACTH tests on a continuous scale, Pearson's correlation coefficient and the Bland-Altman plot were used.
For the Bland-Altman plot (12), the mean difference of the cortisol response including its $95 \% \mathrm{CI}$ and the limits of agreement were calculated. STATA 10 (StataCorp Lp, College Station, TX, USA) was used for statistical analysis.

\section{Results}

\section{Patient characteristics}

We performed both a $1 \mu \mathrm{g}$ ACTH test and a $250 \mu \mathrm{g}$ ACTH test in 207 patients with a time interval of maximum 6 weeks between both tests. The median time interval between the two tests was 7 days. In $8 \%$ of patients only, the time interval was more than 14 days. The $1 \mu \mathrm{g}$ ACTH test was performed before the $250 \mu \mathrm{g}$ ACTH test in $99 \%$ of all tested persons, with intervals between both tests of at least 7 days. In three patients, the $1 \mu \mathrm{g}$ ACTH was performed after the $250 \mu \mathrm{g}$ ACTH test. The time interval between both tests in these three cases was 16,18 , and 24 days respectively.

The patient characteristics are shown in Table 1. Mean age of the patients was 45 years (range 17-80 years). Most patients $(n=109,53 \%)$ were tested for suspected secondary adrenal insufficiency, 98 patients $(47 \%)$ for suspected primary adrenal insufficiency. Basal ACTH levels were higher for patients with suspected primary insufficiency $(43 \mathrm{ng} / \mathrm{l})$ than for patients with suspected secondary insufficiency $(29 \mathrm{ng} / \mathrm{l})$. None of the patients used oral contraceptives at the time of testing. Only a few patients $(3 \%)$ experienced some transient (1-2 min) and non-serious side effects after the administration of the bolus injection of ACTH, such as nausea, sweating, hypotension, and headache.

\section{Comparison of the $1 \mu \mathrm{g}$ and the $250 \mu \mathrm{g}$ ACTH test}

The mean maximal cortisol response was $596 \mathrm{nmol} / \mathrm{l}$ (range 30, 1279) for the $1 \mu \mathrm{g}$ test, and $622 \mathrm{nmol} / \mathrm{l}$ (range 20, 1533) for the $250 \mu \mathrm{g}$ test (Figs 1 and 2).

Table 1 Characteristics of included patients $(n=207)$.

\begin{tabular}{lc}
\hline & Number $(\%)$ \\
\hline Age (mean, range) & $45(17-80)$ \\
Sex & \\
Male & $80(39 \%)$ \\
Female & $127(61 \%)$ \\
Diagnosis & \\
Suspected primary adrenal insufficiency & $98(47 \%)$ \\
DM & $18(9 \%)$ \\
Autoimmune thyroid disease & $44(21 \%)$ \\
Other & $36(17 \%)$ \\
Suspected secondary adrenal insufficiency & $109(53 \%)$ \\
Non-functioning macroadenoma & $28(14 \%)$ \\
Cushing's disease (postoperative) & $20(10 \%)$ \\
Macroprolactinoma & $18(9 \%)$ \\
GH-producing macroadenoma & $15(7 \%)$ \\
Other diseases affecting the pituitary & $28(14 \%)$ \\
\hline
\end{tabular}




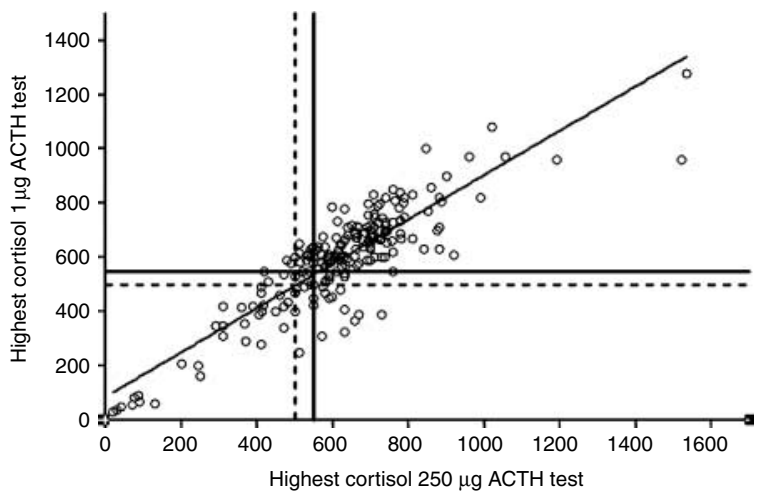

Figure 1 Correlation between the cortisol responses in the $1 \mu \mathrm{g}$ and the $250 \mu \mathrm{g}$ ACTH stimulation tests. The dotted line shows the cut-off value of $500 \mathrm{nmol} / \mathrm{l}$, and the straight line shows the cut-off value of $550 \mathrm{nmol} / \mathrm{l}$.

The 30 min cortisol values of the two tests demonstrated a strong linear correlation (Pearson's correlation coefficient $0.87, P<0.001)$. The mean difference between the responses of the two ACTH tests was $26 \mathrm{nmol} / \mathrm{l}$ (95\% CI 13, 40), showing a marginally higher cortisol response for the $250 \mu \mathrm{g}$ test. The limits of agreement were -173 to $226 \mathrm{nmol} / \mathrm{l}$. There was no increase in difference between the two tests with increasing responses to cortisol.

\section{Normal test responses and degree of concordance}

In 146 of the 207 patients $(71 \%)$, cortisol responses were normal for the $1 \mu \mathrm{g}$ ACTH versus 151 patients (73\%) for the $250 \mu \mathrm{g}$ ACTH test, when applying a cutoff value for a normal cortisol response of $\geq 550 \mathrm{nmol} / \mathrm{l}$. The proportion of patients with a normal cortisol response in both tests was 64\% (132 patients), and both tests showed insufficient responses in 42 other patients $(20 \%)$. The results of both tests were discordant in 33 patients (16\%): 14 patients had a normal cortisol response of the $1 \mu \mathrm{g}$ test, but an abnormal cortisol

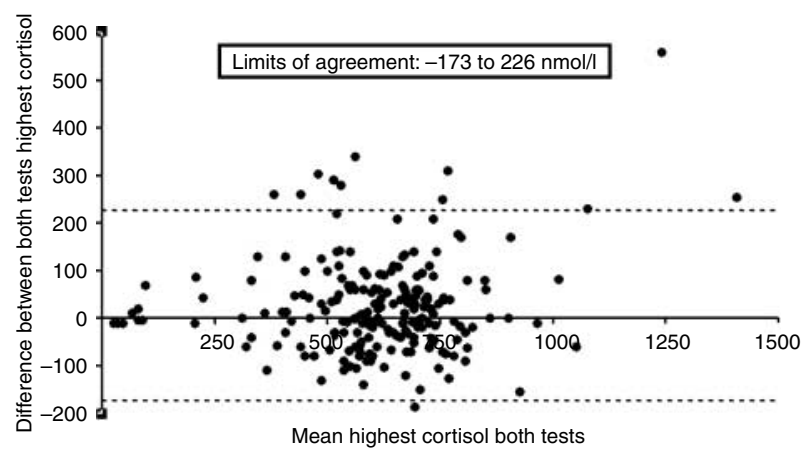

Figure 2 Bland-Altman plot comparing the cortisol responses of the $1 \mu \mathrm{g}$ and the $250 \mu \mathrm{g} \mathrm{ACTH}$ tests. The dotted lines represent the limits of agreement $(-173$ to $226 \mathrm{nmol} / \mathrm{l})$. response of the $250 \mu \mathrm{g}$ test, whereas 19 patients had an abnormal cortisol response during the $1 \mu \mathrm{g}$ test, but a normal cortisol response during the $250 \mu \mathrm{g}$ test. There was no statistical difference in test performance (McNemar, $P=0.49$ ). In patients with a normal cortisol response in the $1 \mu \mathrm{g}$ test, but an abnormal cortisol response in the $250 \mu \mathrm{g}$ test, the cortisol responses for the latter test ranged from 420 to $548 \mathrm{nmol} / \mathrm{l}$. In patients with a normal cortisol response of the $250 \mu \mathrm{g}$ test, but an abnormal cortisol response in the $1 \mu \mathrm{g}$ test, the cortisol responses in the latter test ranged from 310 to $541 \mathrm{nmol} / \mathrm{l}$. Of the 33 patients with discordant results, the treating physicians decided to treat nine patients with corticosteroid substitution. Five of them had a higher cortisol response for the $1 \mu \mathrm{g}$ test, and four had a higher cortisol response of the $250 \mu \mathrm{g}$ test.

When the cut-off value for a normal test response was lowered to a cortisol value of $500 \mathrm{nmol} / \mathrm{l}$, the number of patients with a normal cortisol response increased to $159(77 \%)$ for the $1 \mu \mathrm{g}$ test, and to $172(83 \%)$ for the $250 \mu \mathrm{g}$ test. The proportion of patients with a normal cortisol response in both tests was 154 (74\%); 30 patients $(14 \%)$ had an abnormal cortisol response of both tests. In 23 patients $(11 \%)$, the test results were discordant: 5 patients had a normal cortisol response of the $1 \mu \mathrm{g}$ test but an abnormal cortisol response using $250 \mu \mathrm{g}$, and 18 patients had an abnormal cortisol response with $1 \mu \mathrm{g}$ but a normal cortisol response of the $250 \mu \mathrm{g}$ test. Using a cut-off value of $500 \mathrm{nmol} / \mathrm{l}$, the $250 \mu \mathrm{g}$ test showed more normal cortisol responses than the $1 \mu \mathrm{g}$ test $(\mathrm{McNemar}, P=0.01)$.

\section{Test response in relation to clinical indication: suspected primary versus secondary insufficiency}

In patients suspected of primary adrenal insufficiency $(n=98), 65$ patients $(66 \%)$ had a normal cortisol response in both tests and 17 patients (17\%) had an abnormal cortisol response in both tests. Sixteen patients $(16 \%)$ had discordant test results: 5 patients (5\%) had a normal cortisol response of the $1 \mu \mathrm{g}$ test but an abnormal cortisol response of the $250 \mu \mathrm{g}$ test, and 11 patients $(11 \%)$ had an abnormal cortisol response of the $1 \mu \mathrm{g}$ test but a normal cortisol response of the $250 \mu \mathrm{g}$ test $(\mathrm{McNemar} P=0.21)$.

In those patients suspected of secondary adrenal insufficiency $(n=109), 67$ patients $(61 \%)$ had a normal cortisol response of both tests and 25 patients (23\%) had an abnormal cortisol response of both tests. Seventeen patients $(16 \%)$ had discordant test results: nine patients $(8 \%)$ had a normal cortisol response of the $1 \mu \mathrm{g}$ test and an abnormal cortisol response of the $250 \mu \mathrm{g}$ test; eight (7\%) patients had an abnormal cortisol response of the $1 \mu \mathrm{g}$ test but a normal cortisol response of the $250 \mu \mathrm{g}$ test. There was no statistical difference in test performances $(\mathrm{McNemar} P=1)$. 


\section{Discussion}

The present study analyzed the cortisol response of the $1 \mu \mathrm{g}$ and the $250 \mu \mathrm{g} \mathrm{ACTH}$ tests in a large cohort of patients suspected for adrenal insufficiency. We demonstrated that the $30 \mathrm{~min}$ cortisol response to both tests was almost exactly the same. This is in line with findings from other studies (13). In addition, for cortisol cut-off values of 500 as well as $550 \mathrm{nmol} / \mathrm{l}$, the diagnostic performances of both tests were similar, with a marginally higher proportion of normal test results for the $250 \mu \mathrm{g}$ test.

The major strength of the present analysis is the large number of patients $(n=207)$. This is the largest single center study directly comparing cortisol responses in high and low dose ACTH test in patients suspected for adrenal insufficiency (10). Moreover, in our study, patients tested for primary as well as secondary adrenal insufficiency were included, thereby enhancing the generalizability of the study results. In the present study, cortisol values were obtained $30 \mathrm{~min}$ after ACTH stimulation. The results may therefore not be generalizable to cortisol responses $60 \mathrm{~min}$ after ACTH tests (14). The meta-analysis comparing the $250 \mu \mathrm{g}$ ACTH test with the $1 \mu \mathrm{g}$ ACTH tests showed variability across studies in the optimal timing for measuring cortisol response; importantly, in no study, a statistically significant difference in diagnostic discrimination at $30 \mathrm{~min}, 60 \mathrm{~min}$, or at peak response was shown (10).

A limitation of the present study is that the study does not allow to assess how these tests perform in the diagnosis of adrenal insufficiency, because the reference standard (insulin tolerance test (ITT)) was not included in the design. However, in clinical practice, ACTH tests are often performed as a first step in the diagnostic evaluation of adrenal insufficiency, and subsequent steps are based on these results in combination with the clinical picture (3). However, the results from this study are clinically relevant for two reasons. Firstly, the cortisol responses to both ACTH doses were on average the same. Secondly, the study showed that differences in cortisol response between the two tests can range from $-173 \mathrm{nmol} / \mathrm{l}$ (lower response in the $250 \mu \mathrm{g}$ test) to $226 \mathrm{nmol} / \mathrm{l}$ (higher response in the $250 \mu \mathrm{g}$ test). This indicates that the cortisol response after a $250 \mu \mathrm{g}$ test is not invariably higher than the response in a $1 \mu \mathrm{g}$ test and that the differences in responses can be substantial. The imperfect sensitivity of the ACTH test for the detection of primary adrenal insufficiency (15) might be partly explained by the varying cortisol responses within patients.

Recently, a meta-analysis compared the diagnostic performances between the $1 \mu \mathrm{g}$ ACTH and the $250 \mu \mathrm{g}$ ACTH tests (10). That study showed a better diagnostic performance for the $1 \mu \mathrm{g}$ ACTH test, mainly due to a better sensitivity. We showed that the cortisol responses of both tests were similar. The similarity of the results of both tests might be an argument in favor of performing a $250 \mu \mathrm{g}$ test routinely, because of its higher ease of administration (16). However, the finding that for a cut-off value of $\geq 500 \mathrm{nmol} / \mathrm{l}$ (1), the $250 \mu \mathrm{g}$ test showed a slightly higher proportion of normal test results, is in line with the suggested better sensitivity of the $1 \mu \mathrm{g}$ test $(10,17,18)$.

In conclusion, this study shows that the $1 \mu \mathrm{g} \mathrm{ACTH}$ test and the $250 \mu \mathrm{g}$ ACTH test have a similar cortisol response in patients with suspected adrenal insufficiency. However, in individual patients, the difference in cortisol response of the two tests can be substantial, and the response in the $250 \mu \mathrm{g}$ test is not invariably higher than the response in a $1 \mu \mathrm{g}$ test.

\section{Declaration of interest}

O M Dekkers, J M Timmermans, J W A Smit, and J A Romijn have nothing to declare. A M Pereira reports to have received lecture fees from Novartis and Pfizer.

\section{Funding}

This research did not receive any specific grant from any funding agency in the public, commercial or not-for-profit sector.

\section{References}

1 Arlt W \& Allolio B. Adrenal insufficiency. Lancet $2003 \mathbf{3 6 1}$ 1881-1893. (doi:10.1016/S0140-6736(03)13492-7)

2 Dekkers OM, Pereira AM, Roelfsema F, Voormolen JH, Neelis KJ, Schroijen MA, Smit JW \& Romijn JA. Observation alone after transsphenoidal surgery for nonfunctioning pituitary macroadenoma. Journal of Clinical Endocrinology and Metabolism 200691 1796-1801. (doi:10.1210/jc.2005-2552)

3 Oelkers W. Adrenal insufficiency. New England Journal of Medicine 1996335 1206-1212. (doi:10.1056/NEJM199610173351607)

4 Grinspoon SK \& Biller BM. Clinical review 62: laboratory assessment of adrenal insufficiency. Journal of Clinical Endocrinology and Metabolism 1994 79 923-931. (doi:10.1210/jc.79.4.923)

5 Agha A, Tomlinson JW, Clark PM, Holder G \& Stewart PM. The long-term predictive accuracy of the short synacthen (corticotropin) stimulation test for assessment of the hypothalamicpituitary-adrenal axis. Journal of Clinical Endocrinology and Metabolism 200691 43-47. (doi:10.1210/jc.2005-1131)

6 Dickstein G, Shechner C, Nicholson WE, Rosner I, Shen-Orr Z, Adawi F \& Lahav M. Adrenocorticotropin stimulation test: effects of basal cortisol level, time of day, and suggested new sensitive low dose test. Journal of Clinical Endocrinology and Metabolism 199172 773-778. (doi:10.1210/jcem-72-4-773)

7 Dickstein G, Spigel D, Arad E \& Shechner C. One microgram is the lowest ACTH dose to cause a maximal cortisol response. There is no diurnal variation of cortisol response to submaximal ACTH stimulation. European Journal of Endocrinology 1997137 172-175. (doi:10.1530/eje.0.1370172)

8 Tordjman K, Jaffe A, Trostanetsky Y, Greenman Y, Limor R \& Stern N. Low-dose (1 microgram) adrenocorticotrophin (ACTH) stimulation as a screening test for impaired hypothalamopituitary-adrenal axis function: sensitivity, specificity and accuracy in comparison with the high-dose (250 microgram) test. Clinical Endocrinology 200052 633-640. (doi:10.1046/j. 1365-2265.2000.00984.x)

9 Rasmuson S, Olsson T \& Hagg E. A low dose ACTH test to assess the function of the hypothalamic-pituitary-adrenal axis. Clinical Endocrinology $1996 \mathbf{4 4}$ 151-156. (doi:10.1046/j.1365-2265. 1996.600482.x) 
10 Kazlauskaite R, Evans AT, Villabona CV, Abdu TA, Ambrosi B, Atkinson $\mathrm{AB}$, Choi $\mathrm{CH}$, Clayton $\mathrm{RN}$, Courtney $\mathrm{CH}$, Gonc $\mathrm{EN}$, Maghnie M, Rose SR, Soule SG, Tordjman K \& Consortium for Evaluation of Corticotropin Test in Hypothalamic-PituitaryAdrenal Insufficiency. Corticotropin tests for hypothalamicpituitary-adrenal insufficiency: a metaanalysis. Journal of Clinical Endocrinology and Metabolism 200893 4245-4253. (doi:10. 1210/jc.2008-0710)

11 May ME \& Carey RM. Rapid adrenocorticotropic hormone test in practice. Retrospective review. American Journal of Medicine 1985 79 679-684. (doi:10.1016/0002-9343(85)90517-0)

12 Bland JM \& Altman DG. Statistical methods for assessing agreement between two methods of clinical measurement. Lancet 1986327 307-310. (doi:10.1016/S0140-6736(86)90837-8)

13 Mayenknecht J, Diederich S, Bahr V, Plockinger U \& Oelkers W. Comparison of low and high dose corticotropin stimulation tests in patients with pituitary disease. Journal of Clinical Endocrinology and Metabolism 199883 1558-1562. (doi:10.1210/jc.83.5.1558)

14 Dekkers OM, von Elm E, Algra A, Romijn JA \& Vandenbroucke JP. How to assess the external validity of therapeutic trials: a conceptual approach. International Journal of Epidemiology 201039 89-94. (doi:10.1093/ije/dyp174)

15 Suliman AM, Smith TP, Labib M, Fiad TM \& McKenna TJ The low-dose ACTH test does not provide a useful assessment of the hypothalamic-pituitary-adrenal axis in secondary adrenal insufficiency. Clinical Endocrinology 200256 533-539. (doi:10. 1046/j.1365-2265.2002.01509.x)

16 Wade M, Baid S, Calis K, Raff H, Sinaii N \& Nieman L. Technical details influence the diagnostic accuracy of the 1 microg ACTH stimulation test. European Journal of Endocrinology 2010 162 109-113. (doi:10.1530/EJE-09-0746)

17 Courtney CH, McAllister AS, Bell PM, McCance DR, Leslie H, Sheridan B \& Atkinson AB. Low- and standard-dose corticotropin and insulin hypoglycemia testing in the assessment of hypothalamic-pituitary-adrenal function after pituitary surgery. Journal of Clinical Endocrinology and Metabolism $2004 \mathbf{8 9}$ 1712-1717. (doi:10.1210/jc.2003-031577)

18 Gonźlbez J, Villabona C, Ramn J, Navarro MA, Giménez O, Ricart W \& Soler J. Establishment of reference values for standard dose short synacthen test (250 microgram), low dose short synacthen test (1 microgram) and insulin tolerance test for assessment of the hypothalamo-pituitary-adrenal axis in normal subjects. Clinical Endocrinology 200053 199-204. (doi:10.1046/ j.1365-2265.2000.01028.x)

Received 27 October 2010

Accepted 29 October 2010 